\title{
Ueber „Antistreptokokken-Serum“."1
}

\author{
Von
}

\author{
Dr. Johannes Petruschky.
}

Der schöne Erfolg, den die Serumtherapie bei der Diphtherie zu verzeichnen hat, gab frühzeitig die Anregung, ähnliches auch bei anderen Infectionskrankheiten zu erstreben. Bereits Behring und seine Schüler nahmen Immunisirungsversuche gegen Streptokokken-Infection in Angriff. Nach Behring's Fortgang aus Berlin setzte ich meine Arbeiten mit Streptokokken auch nach dieser, bis dahin Behring allein vorbehaltenen Richtung fort. Auch von anderen Stellen hörte man über derartige Versuche, ohne dass befriedigende Ergebnisse derselben zur Kenntniss kamen.

Da erschien im März 1895 aus Paris die überraschende Nachricht, dass Marmorek aus Wien, der sich bisher nur durch eine theoretische Abhandlung über Streptokokken-Infection bekannt gemacht hatte, das Ziel erreicht habe und demnächst Genaueres über sein Verfahren veröffentlichen werde; gleichzeitig machten Charrin und Roger Mittheilung von günstigen Erfolgen in der Gewinnung von Antistreptokokken-Serum.

Im Frühjahr 1895 erschien eine ausführlichere Mittheilung von Marmorek gleichzeitig in den Annales de l'Institut Pasteur und in der Wiener klinischen Wochensohrift. Die folgende Zeit brachte dann eine Reihe von Mittheilungen über Behandlungsversuche am Menschen, welche mit dem Marmorek'schen Antistreptokokken-Serum unternommen waren. Auch populäre Darstellungen in Tageszeitungen beschäftigten sich mit dem Gegenstand.

Eingegangen am 21. Juli 1896. 
Sogleich nach Erscheinen der Arbeit Marmorek's in den Annales de l'Institut Pasteur wurde die Nachprüfung dieser theoretisch, wie praktisch so verheissungsvollen Versuche im Institut für Infectionskrankheiten in Angriff genommen.

Noch ehe diese Nachprüfung bis zu einem für die Veröffentlichung geeigneten Ergebniss gediehen war, übergab mir ein Berliner College eine Quantität des Antistreptokokken-Serums, welches derselbe auf seine Bitte vom Institut Pasteur erhalten hatte, zur Prüfung im Thierversuch.

Da ich einen zu maximaler Virulenz für Kaninchen angezüchteten Streptococcus (von einem Fall menschlicher Sepsis stammend) stets in Dauerculturen auf Eis vorräthig hielt, schritt ich sofort zur Prüfung der Schutzwirkung des Serums gegen Impfung mit minimalen Mengen dieses Streptococcus. Das Ergebniss war insofern ein überraschendes, als keinerlei Schutzwirkung des Serums gegenüber meinem Streptococcus zu Tage trat.

Hatte ich bei meinen bisherigen eigenen Versuchen auch noch niemals Thiere durch Vorbehandlung mit meinen Serumsorten vom Tode durch diesen Streptococcus retten können, so hatte ich doch hin und wieder Verzögerungen des Todes gegenüber den Controlthieren erlebt, und zwar war in diesen Fällen bei Wundinfection am Ohr nicht die bei den Controlthieren durchweg eintretende rapide Sepsis ohne Localerscheinungen an der Infectionsstelle erfolgt, sondern es trat zunächst eine Röthung. der Infectionsstelle und von hier aus ein mehrere Tage andauerndes, schweres Ohrerysipel ein; später erst erfolgte der Tod durch Allgemeininfection.

Diese Reihenfolge der Erscheinungen, welche ich als Andeutung einer Erhöhung der Widerstandsfähigkeit des inficirten Körpers gegenüber dieser schweren Infection auffassen $z u$ müssen glaubte, hatte ich in mehr oder minder ausgeprägter Weise bei Vorbehandlung mit Serum sehr verschiedener Herkunft (auch von unbehandelten oder anderweitig vorbehandelten Thieren stammend) zuweilen erlebt, so dass ich mich von einer specifischen Wirkung noch nicht hatte überzeugen können.

Die Versuche mit dem Pariser Serum ergaben nun nicht einmal jene Verzögerung des Todes gegenüber den Controlthieren, wie aus beifolgenden Tabellen I und II ersichtlich ist, während z. B. das Hammelserum N. und das Pferdeserum $R$. in diesem wie in den folgenden Versuchen regelmässig diese Wirkung hatte.

Bei den Versuchen, in welchen mit Verdünnungen der StreptokokkenBouillon-Cultur inficirt wurde, um die Versuchsbedingungen dem einzigen von Marmarek veröffentlichten Thierversuche möglichst analog zu gestalten, geschah die Verdünnung ganz nach dem Verfahren, wie ich es bereits in meiner ersten Abhandlung "Ueber Infection mit pyogenen 
Kokken" 1 beschrieben habe. Die Cultur wurde kräftig durchgesehüttelt, dann $1^{\text {eem }}$ derselben in $100^{\mathrm{cen}}$ bezw. $1000^{\mathrm{cm}}$ sterilen Wassers gethan, wiederum kräftig durchgeschüttelt, und von hiır aus - natürlich mit frischen Instrumenten - in derselben Weise weiter verdünnt.

'l'a bello I.

\begin{tabular}{|c|c|c|c|}
\hline $\begin{array}{l}\text { Kaninchen, } \\
\text { mittelgross }\end{array}$ & $\begin{array}{l}\text { Vorbehindelt } \\
\text { am 31./11. mit }\end{array}$ & $\begin{array}{l}\text { Inficirt } \\
\text { am 1.JV. }\end{array}$ & Ausgang \\
\hline 1 & $\begin{array}{l}5 \cdot 0 \text { S'crum Paris } \\
\text { (Institut Pasteur) }\end{array}$ & 을 总 & $3 . / 1 \mathrm{IV} \cdot+$ \\
\hline 2 & $5 \cdot 0$ Menschenserum & $8=$ & Localerscheinungen \\
\hline 3 & $\begin{array}{l}5 \cdot 0 \text { Pferdeserum } \\
\text { (unvorbehandelt) }\end{array}$ & की & an der Impfstelle. \\
\hline 4 & $5 \cdot 0$ Hammelserum $\mathrm{N}$ & क & $\begin{array}{c}\text { 7.IIV. } \dagger \text {; vorher schweres Erysipel } \\
\text { des inficirten Ohres. }\end{array}$ \\
\hline 5 & & 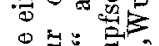 & 4 /IV. t I ohne Localerscheinungen \\
\hline 6 & nicht vorbehandelt & 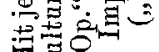 & 3./IV. +$\}^{\text {an der Impfstelle. }}$ \\
\hline 7 & & & 3./IV. † \\
\hline
\end{tabular}

Tabelle II.

\begin{tabular}{|c|c|c|c|c|c|}
\hline $\begin{array}{l}\text { Kaninchen, } \\
\text { mittelgross }\end{array}$ & & $\begin{array}{l}\text { rbehan } \\
11 . / \mathrm{IV}\end{array}$ & delt & $\begin{array}{l}\text { Inficirt } \\
\text { am 12.jIV. }\end{array}$ & Ausgang \\
\hline 1 & 0.25 & Serum & Paris & mit Streptoc. & 14./IV. $t$ \\
\hline 2 & $0 \cdot 25$ & ” & , & „Op." Ver- & Im Blut Streptococeus \\
\hline 3 & $0 \cdot 25$ & " & "” & 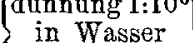 & in Reincultur. \\
\hline 4 & $0 \cdot 25$ & , & , & bosis je $1 \cdot 0$ & 17./IV. $\dagger$ \\
\hline 5 & $0 \cdot 25$ & " & , & $\left(=-\frac{00 m}{1000000}\right)$ & $\begin{array}{l}\text { 31./V. t; im Blut keine Strepto- } \\
\text { kokken (Brustseuche). }\end{array}$ \\
\hline 6 & \multirow{2}{*}{\multicolumn{3}{|c|}{ nicht vorbehandelt }} & & \multirow{2}{*}{$\begin{array}{l}\text { bleibt am Leben. } \\
\text { getödtet } 31 . / \text { V. wegen Brustseuche } \\
\text { (keine Streptokokken). } \\
\text { † 14./IV.; im Blut Streptokokken } \\
\text { in Reincultur. }\end{array}$} \\
\hline 8 & & & & $\left\{\begin{array}{c}\text { Infection wie } \\
\text { bei } 1-5\end{array}\right.$ & \\
\hline
\end{tabular}

Der Grund des aus den Tabellen ersichtlichen Fehlerfolges konnte ein zwiefacher sein: Entweder war das Serum aus unbekannten Gründen unwirksam geworden, oder es besass keine Schutzwirkung gegenüber meinem Streptococcus, der aus einem Fall menschlicher Sepsis stammte, während bekanntlich Marmorek's Streptococeus von einer Angina gewonnen ist. Dass im Institut Pasteur, wo seit mehr als Jahresfrist über Antistreptokokken-Serum gearbeitet wurde, fundamentale Irrthümer vorgekommen wären, hielt ich für ausgeschlossen.

1 Diese Zeitschrift. 1894. Bd. XVII. S. 59. 
Ich wandte mich daher Anfang April dieses Jahres brieflich an Herrn Marmorek mit der Bitte um Uebersendung neuen, wirksamen Serums und womöglich auch seines eigenen Streptococcus, um den Unterschied im Verhalten beider Stämme gegenüber dem Serum aufklären zu können: Die Sendung wurde mir auch von Marmorek in bereitwilligster Weise zugesagt.

Während sich indessen diese Sendung noch verzögerte, erhielt Herr Professor Brieger von einer Serumfabrik in Lyon durch Herrn Dr. Niemann grössere Mengen Antistreptokokken-Serum zu Heilungsversuchen am Menschen. Hiervon wurden mir auf Wunsch des Herrn Geheimrath Koch 2 Flaschen von je 10 cm zur Prüfung im Thierversuch übergeben. $0,1^{\text {eem }}$ des Serums sollte Kaninchen bei Vorbehandlung gegen die' zehnfach tödtliche Dosis schützen.

Tabelle III.

\begin{tabular}{|c|c|c|c|c|c|}
\hline $\mathrm{Nr}$. & $\begin{array}{l}\text { Kaninchen- } \\
\text { Gewicht in } \\
\text { Gramm }\end{array}$ & \multicolumn{2}{|c|}{$\begin{array}{c}\text { Vorbehandelt } \\
\text { am 24./IV. 96. mit }\end{array}$} & $\begin{array}{c}\text { Inficirt am 25.IIV. } 1896 . \\
\text { mit Strept. „0p." } 1: 10^{s} 0 \cdot 1 \\
\left(=\frac{\text { com }}{1000000}\right) \text {, und zwar }\end{array}$ & Ausgang \\
\hline $\mathbf{1}$ & 730 & $0 \cdot 2$. & & an der Vorbehandlungsstelle & $+29 . / \mathrm{IV}$ \\
\hline 2 & 945 & 0.2 & Serum & an anderer Stelle & $+28 . /$ IV. \\
\hline 3 & 980 & $0 \cdot 1$ & Niemann & an der Vorbehandlungsstelle & $+27 . / \mathrm{IV}$ \\
\hline 4 & 780 & $0 \cdot 1$ & & an anderer Stelle & $+1 . / \mathrm{V}$ \\
\hline 5 & 870 & 0.2 & & an der Vorbehandlungsstelle & bleibt am Leben. \\
\hline 6 & 785 & 0.2 & Hammel. & an anderer Stelle & desgl. \\
\hline 7 & 800 & 0.1 & serun & an der Vorbehandlungsstelle & $+29 . /$ IV. \\
\hline 8 & 900 & $0 \cdot 1$ & & an anderer Stelle & bleibt am Leben. \\
\hline 9 & 750 & $0 \cdot 2$ & & an der Vorbehandlungsstelle & desgl. \\
\hline 10 & 730 & 0.2 & Aqua & an anderer Stelle & $+28 . / \mathrm{IV}$ \\
\hline 11 & 650 & $0 \cdot 1$ & destillata & an der Vorbehandlungsstelle & $+30 . / \mathrm{IV}$ \\
\hline 12 & 1280 & $0 \cdot 1$ & & an anderer Stelle & $+1 . / \mathrm{V}$. \\
\hline 13 & 1000 & & iicht & am Rücken & bleibt am Leben. \\
\hline 14 & 1040 & vork & handelt & am ohr & desgl. \\
\hline
\end{tabular}

Tabelle IV.

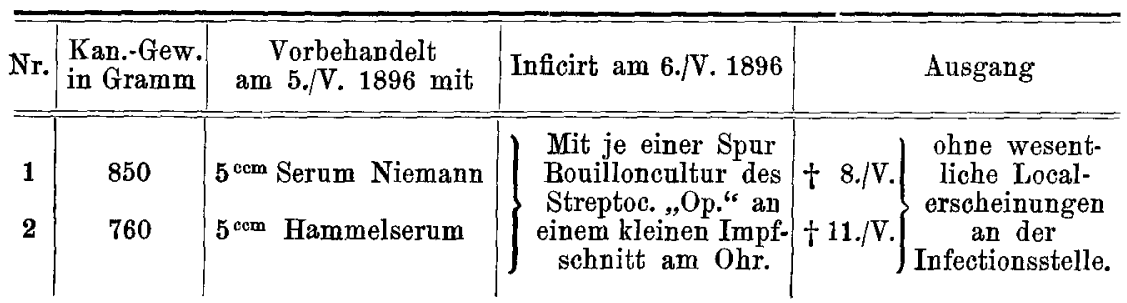


Auch diese Prüfung ergab (wie aus den Tabellen III u. IV ersichtlich ist) ein vollständig negatives Resultat. Das herum schützte gegen meinen Streptococcus nicht, wiewohl ich hei den Verdünnungsversuchen mit der geringsten, noch nicht gan\% sicher tïdtlichen I)osis arbitete (2 nicht vorbehandelte, 1 mit destillirtem Wasser vorbehandeltes und 3 mit gewöhnlichem Hammelserum vorbehandelte 'Thiere blieben am leeben, während sämmtliche 4 mit Niemannschen Serum vorbehandelte Thiere an Streptokokken-Infection eingingen).

Nach Lage der Sache liegt hier, wie bei allen äbrigen Infectionen mit stark verdünnten Culturen die Annahme am nächsten, dass es sich bei den überlebenden Thieren um F'ehl-Infection handelt, zumal da die überlebenden Thiere niemals Krankheitserseheinungen zeigten und an Gewicht zunahmen. Der Versuch hätte also sehr wohl auch zufällig so ausfallen können, dass die mit Niemann's Serum vorbehandelten Thiere von der Infection verschont blieben, es hätte dann noch weiterer Versuche bedurft, um das Ergebniss einwandfrei erscheinen zu lassen. Jedenfalls zeigt dieser Versuch, dass die Zahl der zum Versuch verwendeten Thiere bei dieser Versuchsanordnung keine zu geringe sein darf, wenn man Irrthümern entgehen will.

Inzwischen erschien die Mittheilung von Méry, dass Marmorek's Serum nicht gegen einen von Méry aus einem Scarlatinafall isolirten Streptococcus, wohl aber gegen Marmorek's Streptococcus selbst schützt. Die Einzelheiten der angestellten Thierversuche wurden nicht mitgetheilt. Ferner wurden mehrere Mittheilungen über Anwendung des Marmorek'schen Serums am Menschen bekannt, von denen wohl die bemerkenswerthesten die der französisehen Geburtshelfer sind, welche einstimmig constatirten, dass ,in ihren Händen wenigstens" das Marmorek'sche Serum keine Heilwirkungen bei Puerperalfieber entfalte.

Am 16./V. 1896 erhielt ich nun von Marmorek $20^{\mathrm{cem}}$ seines Serums, eine Cultur seines Streptococcus in Ascites-Bouillon und mehrere Röhrehen steriler Ascites-Bouillon in abgeschmolzenen Röhrchen.

Die Cultur bestand aus nicht sehr langen, wenig gebogenen Streptokokkenketten; dieselbe wurde ausschliesslich auf dem in verschiedene Röhrchen vertheilten Marmorek'schen Nährboden fortgepflanzt und die Reinheit der Cultur stets durch Ausstrich auf Agar, auf dem der Streptococcus gut wuchs, controlirt. Auf der von mir verwendeten Bouillon wuchs der Marmorek'sche Streptococcus kleinflockig und etwa ebenso üppig wie auf der von Marmorek gesandten Ascites-Bouillon; ich war demgemäss sehr gespannt, ob die Marmorek'sche Cultur in der von Marmorek angegebenen starken Verdünnung von 1:100000000 noch regelmässig Keime in jedem Cubikcentimeter enthalten werde, da nach 
meinen bisherigen Erfahrungen in der Verdünnung von 1:1000000 (also in der hundertfach geringeren Verdünnung) stets die Grenze erreicht war, bei welcher man eben noch darauf rechnen konnte, in einem Cubikcentimeter noch eine entwickelungsfähige Keimgruppe - von einzelnen Keimen kann man bei Streptokokken wohl kaum sprechen - anzutreffen. Die schützende Dosis des Serums sollte nach Marmorek's beifolgender Angabe $0.05^{\mathrm{cem}}$ gegen die 24 Stunden später verabfolgte "10fach tödtliche“ Infectionsdosis sein.

Zunächst wurde noch an demselben Tage eine Prüfung des frisch gesandten Serums gegenüber meinem virulenten Streptococcus eingeleitet.

Tabelle V.

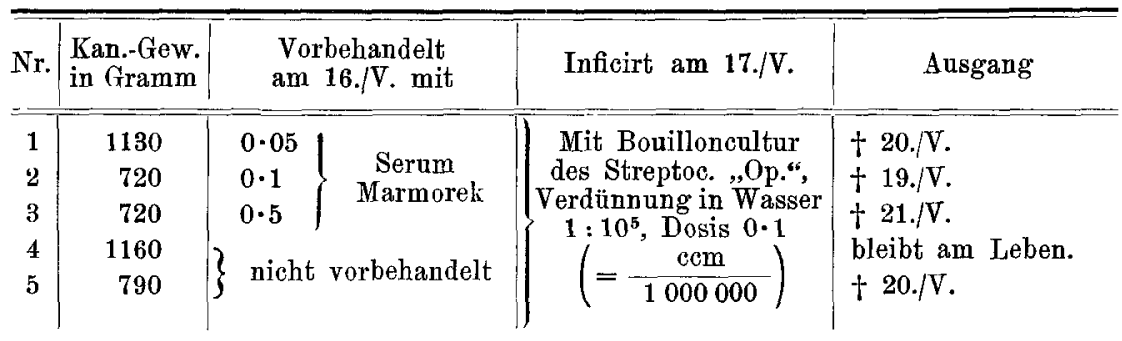

Wie aus der Tabelle V ersichtlich, blieb ein Controlthier am Leben, während das andere nebst sämmtlichen drei vorbehandelten Thieren an Streptokokkeninfection starben; es hatte also gegen die eben tödtliche Dosis meines Streptococcus nicht einmal die nach Angabe Marmorek's gegen die 10 fache Dosis 10 fach schützende Menge $(0 \cdot 5)$ ausgereicht.

Am 18./V. wurde die Prüfung der Schutzkraft dos. Serums gegen Marmorek's Streptococcus selbst vorgenommen, und zwar gleichzeitig die Vorbehandlung mit kleinen Dosen (von 0.05 bis 0,2 ) gegen die Infection mit verdünnter Cultur (Tabelle VI) und die Vorbehandlung mit einer erheblich grösseren Dosis (5.0) gegen die nach meinen Erfahrungen zuverlässigere Wundinfection am $\mathrm{Ohr}$ (Tabelle VII).

Bei der Infection mit verdünnter Cultur verwendete ich nach Marmorek's Vorgang ${ }^{1}$ ein Milliontel Cubikcentimeter, inficirte aber gleichzeitig drei Controlthiere mit dieser Dosis, sowie drei andere mit der 100 fach geringeren Dosis, um mich über die Grenze der Infectionsmöglichkeit zu vergewissern. Gleichzeitig brachte ich in drei Röhrchen einer Nährbouillon, auf welcher der Marmorek'sche Streptococcus üppig wuchs, je ein Milliontel Cubikcentimeter dẹr Cultur. Bei dem Ergebniss zeigte sich eine völlige Uebereinstimmung mit meinen bisherigen Erfahrungen

${ }^{1}$ Annales de l'Institut Pasteur. 1895. 
Tabelle VI.

\begin{tabular}{|c|c|c|c|c|}
\hline Nr. & $\begin{array}{c}\text { Kaninchen- } \\
\text { Gewicht in } \\
\text { Gramm }\end{array}$ & $\begin{array}{l}\text { Vorbehindelt } \\
\text { am 18./V. 1nit }\end{array}$ & $\begin{array}{c}\text { Inficirt am 19./V. mit } \\
\text { Aseites-Bouillon-Cultur } \\
\text { des Streptoc. Marmoreli } \\
\text { (48stiondigr) }\end{array}$ & Ausgang \\
\hline 1 & 1500 & $0 \cdot 05$ & & $+23 . /$ V. $^{1}$ \\
\hline 2 & 1700 & $0 \cdot 1$ & & bleibt am Iteben \\
\hline 3 & 1665 & Serum & Verdünnung $1: 10^{5}$ & desgl. \\
\hline 4 & 1790 & Marmorek & in Wasser, & $+21 . N{ }^{1}$ \\
\hline 5 & 1230 & $0 \cdot 2$ & Dosis $0 \cdot 1$ & bleibt am Leben \\
\hline 6 & 1220 & & $\left.=-\frac{\mathrm{cm}}{1}\right)$ & $+22 . / V .{ }^{1}$ \\
\hline 7 & 910 & nicht & $(1.000 \cdot 000)$ & $+7 . /$ VI. $^{2}$ \\
\hline 8 & 890 & vorbehandelt & & bleibt am Leben \\
\hline 9 & 1420 & & Verdünnung $1: 10^{8}$ & \\
\hline 10 & 1450 & nicht & in Wasser, Dosis 1.0 & bleiben dauernd \\
\hline 11 & 860 & vorbehandelt & $\int\left(=\frac{\mathrm{ccm}}{100 \cdot 000 \cdot 000}\right)$ & am Leben \\
\hline
\end{tabular}

Tabelle VII.

\begin{tabular}{|c|c|c|c|c|}
\hline Nr. & $\begin{array}{c}\text { Kaninchen- } \\
\text { Gewicht in } \\
\text { Gramm }\end{array}$ & $\begin{array}{l}\text { Vorbehandelt } \\
\text { am 18./V. mit }\end{array}$ & Inficirt am 19./V. & Ausgang \\
\hline 1 & 1470 & 5.0 Serum Marmorek & mit je einer Spur & †21./ V. (nach 2Tagen) \\
\hline 2 & 1480 & 5.0 Pferdeserum $R$. & 48 stündiger Ascites- & + 25./V.(nach 6 Tagen $)$ \\
\hline 3 & 1330 & 5.0 Hammelserum & Bouillon-Cultur des & + 21./V. (nach 2 Tagen) \\
\hline 4 & 1280 & $5 \cdot 0$ Hammelserum $\mathrm{N}$. & $\begin{array}{l}\text { Streptoc. Marmorek } \\
\text { an einem kleinen }\end{array}$ & † 24./V. (nach 5 Tagen $)^{1}$ \\
\hline 5 & 1200 & nicht vorbehandelt & Impfschnitt am ohr & $+21 . /$. (nach 2 Tagen) \\
\hline
\end{tabular}

${ }^{1}$ Bei den Thieren 2 und 4 trat schweres Erysipel des inficirten Ohres ein; bei den übrigen Thieren keine wesentlichen Localerscheinungen. Todesursache bei allen: Streptokokken-Sepsis.

an meinen eigenen Streptokokken und eine auffällige Abweichung von den Angaben Marmorek's in der mehrfach eitirten Veröffentlichung. Die drei mit $\frac{\mathrm{ccm}}{100000000}$ inficirten Thiere blieben sämmtlich am Leben und ohne Krankheitserscheinungen; von den drei mit $\frac{\text { cem }}{\mathbf{1 0 0 0 0 0 0}}$ inficirten Thieren starb nur eins (am 3. Tage nach der Infection), während die beiden anderen am Leben blieben. Von letzteren ging dann am 19. Tage nach der Infection das eine an Gregarinose ein (im Blut fanden sich weder mikro- 
skopisch noch culturell Streptokokken), während das dritte dauernd am Leben blieb. Von den drei mit $\frac{\mathrm{ccm}}{1000000}$ besäeten Bouillonröbrchen blieben zwei dauernd steril, in dem dritten zeigte sich eine Verunreinigung, aber keine Streptokokken.

Hiernach müsste man $\frac{c c m}{1000000}$ als die noch nicht sicher tödtliche Dosis ansehen. So konnte es nicht als verwunderlich erscheinen, dass auch von den fünf vorbehandelten Thieren drei am Leben blieben; um so auffälliger aber war es, dass zwei derselben ziemlich rasch an Streptokokkeninfection starben, und zwar ein mit der grösstẹn Dosis $(0 \cdot 2)$ vorbehandeltes noch früher als das einzige erlegene Controlthier, und das mit 0.05 (der angeblich gegen die 10fach tödtliche Dosis schützenden Menge) vorbehandelte Thier am 4. Tage nach der Infection.

Auch die Prüfung gegen Wundinfection fiel völlig negativ aus. Das mit 5 eem Marmorek'schen Serums vorbehandelte Thier starb, gleichzeitig mit zwei Controlthieren, am 2. Tage nach der Infection ohne wesentliche Localerscheinungen an der Infectionsstelle, während zwei andere Controlthiere ein Ohrerysipel durchmachten und erst am 5. bezw. 6. Tage nach der Infection erlagen. Ueber das Serum, mit welchem diese Controlthiere vorbehandelt waren, können hier noch keine näheren Angaben gemacht werden; dieselben Serumsorten haben auch in den späteren Versuchen Andeutungen einer schützenden Eigenschaft gegenüber der Streptokokkeninfection entfaltet. Augenfällig ist jedenfalls, dass dieselbe Dosis des Serums Marmorek's weder in diesem, noch in den folgenden Versuchen auch nur eine ähnliche Andeutung von Schutzwirkung gegenüber dem eigenen Streptococcus Marmorek's zeigte.

In meiner Sammlung befand sich noch ein anderer, von einem Fall septischer Tuberculose stammender Streptococcus, den ich nach Erscheinen der Marmorek'schen Publikation auf Wunsch von Herrn Geheimrath Koch ohne Benutzung der Marmorek'schen Serumbouillon zu maximaler Virulenz für Kaninchen einfach durch Thierpassagen angezüchtet hatte. Auch diesem gegenüber prüfte ich die Sehutzwirkung des Marmorek'schen Serums, und zwar unter Anwendung der sicheren Methode der Wundinfection.

Tabelle VIII zeigt das Ergebniss. Das mit $5^{\text {cem }}$ des Marmorek'schen Serums vorbehandelte Kaninchen starb gleichzeitig mit dem gar nicht vorbehandelten am Abend des Tages, der der Infection folgte, ein mit gewöhnlichem Hammelserum vorbehandeltes Controlthier am Morgen des nächsten Tages, ein mit Pferdeserum vorbehandeltes am 3. Tage nach der Infection. Die beiden Controlthiere, welche mit den bereits im vorigen Versuch verwendeten Serumsorten R. und N. vorbehandelt worden waren, 
machten wiederum ein Ohrerysipel durch und starben erst am 6. Tage nach der Infection.

Tabelle VIII.

\begin{tabular}{|c|c|c|c|c|}
\hline $\mathrm{Nr}$. & $\begin{array}{c}\text { Kaninchen- } \\
\text { Gewicht in } \\
\text { Gramm }\end{array}$ & $\begin{array}{l}\text { Vorbehandelt } \\
\text { am. 18./V. mit }\end{array}$ & Inficirt am 19./V. & Ausgang \\
\hline 1 & 1760 & 5.0 Serum Marmorek & mit je einer Spur & † $24 . / V \cdot($ nach $11 / 2 \mathrm{Tg})$. \\
\hline 2 & 930 & 5.0 Pferdeserum & 24 stündiger Bouillon- & t 26./V.(nach 3 Tagen) \\
\hline 3 & 1030 & 5.0 Pferdeserum $R$. & $\begin{array}{l}\text { Cultur meines Streptoe } \\
\text {.Mx." (von septischer }\end{array}$ & $+29 . /$ V. (nach 6 Tagen $^{1}$ \\
\hline 4 & 1510 & 5.0 Hammelserum & (Tuberculose stammend) & † 25./V.(nach 2 'lagen) \\
\hline 5 & 1325 & 5.0 Hammelserum $\mathrm{N}$. & an einem kleinen & † 29./V.(nach 6 'lagen $)^{1}$ \\
\hline 6 & 1420 & nicht rorbehandelt & Impfschnitt am Ohr & $+24 . / V .(n a c h ~ 11 / 2 \mathrm{Tg})$. \\
\hline
\end{tabular}

1 Bei den Thieren 3 und 5 trat schweres Erysipel des inficirten Obres ein, bei den übrigen Thieren keine wesentlichen Livealerseheinungen. Todesursache bei sämmtlichen Thiəren: Streptokokken-Sepsis.

Nun suchte ich noch einige Einwürfe zu berücksichtigen, die von Marmorek gegen meine Versuchsanordnung gemacht werden könnten. Bei der Wundinfection am Ohr könnte die verwendete Dosis zu gross erscheinen, da die inficirende Platinöse direct in die unverdünnte Cultur getaucht und mit der befeuchteten Oese ein kleiner Impfschnitt am Ohr bestrichen wurde. In der That glaube auch ich, dass hierbei nicht einzelne Keime, sondern stets eine grössere Anzahl von Keimgruppen zur Verimpfung gelangen. Die Infection wird dadurch eine sicherere, als bei der Einspritzung stark verdünnter Culturen; dennoch kann von einer „Masseninfection" keine Rede sein. Ueberdies erlaubt der entweder rapid acute oder mehr chronische Verlauf der Erkrankung, sowie das gerade bei dieser Art der Infection besonders gut zur Anschauung kommende Anftreten von Localerscheinungen an der Infectionsstelle (Erysipel) einen Rückschluss auf die - natürliche oder künstlich erhöhte - Widerstandsfähigkeit des inficirten Thieres, gemäss den Erfahrungen, die ich bereits früher beim Thierversuch und durch Beobachtung am Menschen gewonnen hatte. ${ }^{1}$ Hiernach ist das Entstehen eines Erysipels derAusdruck eines bestimmten (mittleren) Verhältnisses zwischen der Virulenz des inficirenden Streptococcus und der Widerstandsfähigkeit des inficirten Organismus. Ist bei gegebener Virulenz die Widerstandsfähigkeit erheblich geringer, so entsteht nicht Erysipel, sondern acute Sepsis ohne wesentliche Localerscheinungen an der Infectionsstelle; ist dieselbe erheblich grösser, so verläuft die Infection abortiv.

${ }^{1}$ Vgl. diese Zeitschrift. Bd. XVIII. S. $413 \mathrm{ff}$. „Die verschiedenen Erscheinungsformen der Streptokokken-Infection n. s. w.“ 
Nach alledem muss mir die Schutzkraft eines Serums, welches bei dieser Art der Wundinfection, prophylactisch angewendet, auch nicht eine Andeutung einer Erhöhung der Widerstandsfähigkeit des inficirten Thieres liefert, sehr problematisch erscheinen, um so mehr natürlich, wenn auch die mit Culturverdünnungen angestellten Versuche keine Schutzkraft ersehen lassen.

Ein zweiter Punkt, der als Einwand benutzt werden könnte, ist der, dass ich die Verdünnungen mit sterilem Wasser nicht mit Bouillon hergestellt habe, wiewohl über die zu verwendende Verdünnungsflüssigkeit bei Marmorek keine Angabe zu finden ist und es nach meinen früheren Erfahrungen völlig gleichgültig, ob man mit Bouillon oder mit Wasser verdünnt, vorausgesetzt, dass man die Verdünnungen sogleich nach der Herstellung benutzt, was wohl als selbstverständlich angesehen werden kann. Um indessen auch diesem Einwand aus dem Wege zu gehen, habe ich noch einen Versuch angestellt, bei welchem die Infection mit der durch Bouillon verdünnten Marmorek'schen Cultur bewirkt wurde. Gleichzeitig gestaltete ich die Versuchsanordnung so, dass zwei der vorbehandelten Thiere an derselben Stelle inficirt wurden, an welcher das Serum Tags zuvor eingespritzt worden war.

Tabelle IX.

\begin{tabular}{|c|c|c|c|c|}
\hline Nr. & 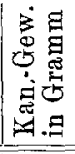 & $\begin{array}{l}\text { Vorbehandelt } \\
\text { am } 27 . / \mathrm{V} \text {. mit }\end{array}$ & $\begin{array}{l}\text { Inficicrt am 28./V. mit } \\
\text { Ascites-Bouillonoultur des } \\
\text { Streptococcus Marmorek }\end{array}$ & Ausgang \\
\hline 1 & 8180 & 0.25 & & bleibt ann Ixben. \\
\hline 2 & 1885 & $0 \cdot 25$ & & 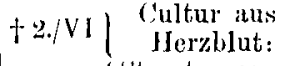 \\
\hline 3 & 1810 & Marmorek & $\begin{array}{l}\text { Verdünnung } 1: 10^{5} \\
\text { iu }\end{array}$ & † 2./VI. $\begin{array}{l}\text { Streptococeus } \\
\text { in Reincultur }\end{array}$ \\
\hline 4 & 1665 & $0 \cdot 25$ & $(-\mathrm{cem})$ & bleibt am Leben. \\
\hline 5 & 1660 & $0 \cdot 25$ & $=-\overline{1000000}$ & desgl. \\
\hline 6 & 1670 & & und zwar Kaninchen 3 u. 4 & desgl. \\
\hline 7 & 1665 & & an derVorbehandlungsstelle. & desgl. \\
\hline 8 & 880 & nicht vorbehandelt & & $\begin{array}{l}\text { + 30./V. (Cultur: } \\
\text { Streptococcus rein). }\end{array}$ \\
\hline 9 & 905 & & & bleibt am Leben. \\
\hline 10 & 970 & & $\begin{array}{l}\text { Verdünnung } 1: 10^{7} \\
\text { in Bouillon, Dosis } 1 \cdot 0\end{array}$ & desgl. \\
\hline 11 & 800 & nicht vorbehandelt & $\left(=\frac{\mathrm{cem}}{10000000}\right)$ & desgl. \\
\hline 12 & 975 & & $\begin{array}{l}\text { Verdünnung } 1: 10^{7} \\
\text { in Bonillon Dosis } 0 \cdot 1\end{array}$ & desgl. \\
\hline 13 . & 880 & nicht vorbehandelt & $\left(=\frac{\mathrm{cem}}{100000000}\right)$ & $\begin{array}{l}+30 . / V . \quad \text { (Cultur: } \\
\text { Streptococcus rein). }\end{array}$ \\
\hline
\end{tabular}


Als Controlthiere dienten in diesem Versuche acht Kaninchen, von denen vier $\frac{\mathrm{ccm}}{1000000}$, zwei $\frac{\mathrm{ccm}}{10000000}$, und zwei $\overline{100000000}$ ohne Vorbehandlung erhielten. Aüsserdem wurden sieben Bouillonröhrchen mit folgenden Mengen verdünnter Cultur besäet: zwei Röhrchen mit $\frac{\mathrm{ccm}}{100000000}$, zwei mit $\frac{\text { ccm }}{10000000}$, und je eins mit $\frac{c \mathrm{~cm}}{1000000}, \frac{2 \mathrm{ccm}}{1000000}$ und $\frac{3 \mathrm{ccm}}{1000000}$. Die sieben Röhrchen blieben sämmtlich steril, während von den acht Controlthieren zwei starben, und zwar eins mit der Dosis $\frac{\text { ecm }}{1000000}$ und eins mit der Dosis $\frac{\mathbf{c e m}}{100000000}$. Der Tod dieses letzteren Thieres - übrigens des einzigen Thieres, welches in meinen Versuchen an dieser Dosis starb - beweist nach meiner Auffassung, dass die Virulenz des Streptococcus sich maximal erhalten hatte, und offenbar jedes Thier, welches bei der Infection lebende Keime erhielt, auch zu Grunde ging.

Von den vorbehandelten Thieren, von denen jedes $0.25^{\mathrm{ccin}}$, also die nach Marmorek's Angabe gegenüber der 10 fach tödtlichen Dosis 5 fach schützende Menge Serum erhalten hatte, starben zwei, darunter auch eins, welches an der Vorbehandlungsstelle inficirt worden war, und zwar beide an reiner Streptokokkeninfection. In diesem Versuche hatte sich an dem Verhalten der Controlthiere und der besäeten Bouillonröhrchen wiederum deutlich gezeigt, dass die Dosis von 1000 ock auch bei der Verdünnung durch Bouillon offenbar noch zu gering ist, um mit einiger Sicherheit lebende Keime zu enthalten und daher erfolgreiche Infection erwarten zu lassen. Ausserdem war mir aufgefallen, dass die Marmorek'sche Streptokokkencultur auf der Marmorek'schen Ascitesbouillon im Brütschrank bereits nach 24 Stunden üppig gewachsen war, so dass man annehmen konnte, es sei vielleicht nach 48 Stunden ein Theil der Keime schon abgestorben, wie das in gewöhnlicher Bouillon in der That die Regel zu sein pflegt. Ich benutzte daher zu einem letzten Versuche, um die Chance der erfolgreichen Infection gleichmässiger zu gestalten, eine 24stündige Cultur in Ascitesbouillon und eine Dosis von $\frac{\mathrm{ccm}}{100 \overline{000}}$. (S. Tabelle X.)

Auch hier war das Ergebniss ein mit den bisherigen Versuchen völlig übereinstimmendes, da von sechs vorbehandelten Thieren vier, von drei Controlthieren zwei starben (je $2 / 3$ Mortabilität). Eine Schutzwirkung des Serums kann daher auch, aus diesem Versuche in keiner Weise abgeleitet werden. 
Tabelle X.

\begin{tabular}{|c|c|c|c|c|}
\hline Nr. & 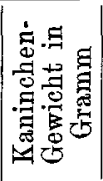 & $\begin{array}{l}\text { Vorbehandelt } \\
\text { am 3./VI. mit }\end{array}$ & $\begin{array}{l}\text { Inficirt am 4./VI. mit Streptoc. } \\
\text { Marmorek (48 stündige Cultur } \\
\text { in Ascites-Bouillon). } \\
\text { Verdünnung } 1: 10^{5} \text {. Dosis } 1 \cdot 0 \\
\quad=\left(\frac{\mathrm{cem}}{100000}\right) \text {, und zwar }\end{array}$ & Ausgang \\
\hline 1 & 1650 & $\begin{array}{r}0 \cdot 25 \text { Sérum Marmorek } \\
\text { LH(links hinten injic.) }\end{array}$ & LH $\quad \frac{\text { an der }}{\text { Vorbehandlonosstelle }}$ & bleiben am \\
\hline 2 & 1480 & $0.25 \mathrm{LH}$ & $\checkmark$ orbehandlungsstelle & \\
\hline 3 & 1330 & $0.25 \mathrm{LH}$ & $n$ dorcolban Saito & $+6 . /$ VI. \\
\hline 4 & 1200 & $0.25 \mathrm{LH}$ & n derselben Seite` & $+9 . / \mathrm{VI}$ \\
\hline 5 & 1150 & $0.25 \mathrm{LH}$ & dov andaron Soit & $+7 . / \mathrm{VI}$ \\
\hline 6 & 1130 & $0 \cdot 25 \mathrm{LH}$ & LV\} an der anderen Seite & $+8 . / \mathrm{VI}$ \\
\hline 7 & 1350 & & & bleibt am Leben \\
\hline 8 & 1250 & nicht vorbehandelt & ebenso inficirt (RV) & $+7 . / \mathrm{VI}$. \\
\hline 9 & 1340 & & & $\dagger 6 . /$ VI. \\
\hline
\end{tabular}

Das Ergebniss meiner Versuche ist also ein von den Mittheilungen Marmorek's durchaus abweichendes, und ich muss, wenn ich mich ähnlich wie die französischen Gynäkologen ausdrücken will, constatiren, dass „,in meinen Händen wenigstens" das Marmorek'sche Serum nicht einmal im Thierversuch eine Schutzwirkung gegenüber Marmorek's Streptococcus erkennen liess. Ebenso wenig entfaltete dasselbe eine Schutzwirkung gegenüber den in meiner Sammlung befindlichen, für Kaninchen maximal virulenten Streptokokken.

Besonders hervorheben möchte ich noch, dass auch die Behauptung Marmorek's, es sei ihm durch Verwendung seines besonderen Nährbodens (Serum-Bouillon) gelungen, einen Streptococcus von „bisher unbekannter Virulenz" zu gewinnen, dessen sicher tïdtliche Iosis für Kaninchen $\frac{c \mathrm{~cm}}{10000000}$ sei, durch meine Versuche keine Bestätigung gefunden hat. Aus allen in obigen Tabellen enthaltenen. Versuchen ergiebt sich vielmehr, dass sowohl bei dem Streptococcus Marmorek, als bei meinen Streptokokken die Dosis von $\frac{c \mathrm{~cm}}{1000000}$ und bei dem Marmorek'schen auch die von $\frac{c \mathrm{~cm}}{100000}$ eine noch nicht sicher tödtliche Dosis ist. Dies entspricht vollkommen meinen früheren Infectionsversuchen mit stark verdünnten Streptokokken-Culturen, die ich im Anschluss an die Blutuntersuchungen bei mensehlicher Sepsis angestellt habe. In diesen Versuchen habe ich bereits festgestellt, dass manche Streptokokken-Stämme,

${ }^{1}$ Vgl. diese Zeitschrift. 1894. Bd. XVII. S. 59. 
welche direct aus dem Blut Sepsiskranker stammen, für Mäuse in einer Dosis von $\underset{1000000}{c 0}$ bereits tödtlich sein können. Aus gleichzeitigen Aussaatversuchen habe ich geschlossen, dass die durchgeschüttelten Bouillonculturen dieser Streptokokken etwa 10-20 Millionen entwickelungsfähige Keime pro Cubikcentimeter enthielten. Bei allen. seitherigen Untersuchungen ist mir kein Streptococcus begegnet, der eine grïssere Virulenz für irgend eine Thierspecies, oder, was bei gleich maximaler Virulenz auf dasselbe hinauskäme, eine grössere Wachsthumsüppigkeit auf irgend einem Nährboden zur Entfaltung gebracht hätte. Dies trifft auch für Marmorek's Streptococous und Marmorek's Nährboden zu; die Wachsthumsüppigkeit ist hier eher noch etwas geringer, da sonst, selbst bei nicht völlig gleichmässiger Keimvertheilung in den Verdünnungen die Dosis von $\frac{\mathrm{cem}}{1000000}$ und namentlich die von $\frac{\text { com }}{100000}$ sicherer tödtlich gewirkt haben müsste, als es in den eben mitgetheilten Versuchen der Fall gewesen ist.

Zum Schluss möchte ich noch bemerken, dass zwei Proben des Pariser Serums anf Keimgehalt untersucht und sehr reich an lebenden Spaltpilzen gefunden wurden. Aus dieser Thatsache, die übrigens für die Anwendung des Serums am Menschen keineswegs gleichgültig sein dürfte, glaube ich schliessen zu können, dass ein Conservirungsmittel den betreffenden Serumproben nicht beigefügt war.

\section{Ergebnisse.}

1. Zweitägige Culturen des Streptococcus Marmorek in der von ihm selbst hergestellten Ascitesbouillon ${ }^{1}$ bewirken in der Dosis von $0.000001 \mathrm{cem}$ (d. h. einem Milliontel Cubikcentimeter) meistens, aber nicht sicher eine tödtliche Streptokokkeninfection bei Kaninchen.

2. Die Dosis von $\frac{c e m}{10^{8}}$, d. h. ein Hundertmilliontel Cubikcentimeter inficirt Kaninchen nur ausnahmsweise, ist daher keineswegs - wie $\mathbf{M}$ armorek angiebt - als sicher tödtliche Dosis zu betrachten.

3. Die Wachsthumsüppigkeit der Streptokokken ist in Marmorek's Ascitesbouillon nicht grösser als in guter Nährbouillon. Der Keimgehalt einer ausgewachsenen Cultur beträgt nach meinen Berechnungen etwa 2 bis 20 Millionen lebender Keime bezw. Keimgruppen pro Cubikcentimeter.

${ }^{1}$ Serum-Bouillon ist zur Züchtung von Streptokokken vor Marmorek bereits von v. Lingelsheim angewendet worden.

Zeitsehr. f. Hygiene. XXII. 
498 Johannes Petruschky: Über Antistreptokokken-SERUm.

4. Ueber einen Streptococcus, welcher in der Dosis von einem Milliontel Cubikcentimeter Mäuse tödtete, also für dieselben maximale Virulenz besitzt, habe ich bereits früher berichtet.

Maximale Virulenz für Kaninchen besitzen zwei von mir conservirte Streptokokkenculturen; eine derselben bereits seit mehreren Jahren. Die Virulenz des Streptococcus Marmorek ist etwa die gleiche. Neue Ergebnisse über die Virulenzhöhe von Streptokokkenculturen sind somit durch Marmorek's Versuche nicht erzielt worden.

5. Eine Schutzwirkung gegen die Infection mit den genannten Streptokokenstämmen zeigte weder das aus Paris, noch das aus Lyon gelieferte Serum; und zwar weder gegen die Infection mit stark verdünnten Culturen, noch gegen die Wundinfection. Die Anwendung des Serums geschah in jedem Falle 24 Stunden vor der Infection.

6. Die genannten Serumsorten können daher auf Grund der vorliegenden Thierversuche zu therapeutischen Versuchen am Menschen nicht empfohlen werden.

7. Ein sicherer Beweis für die Möglichkeit einer Serumtherapie bei Streptokokkeninfection ist bisher nicht erbracht worden. 